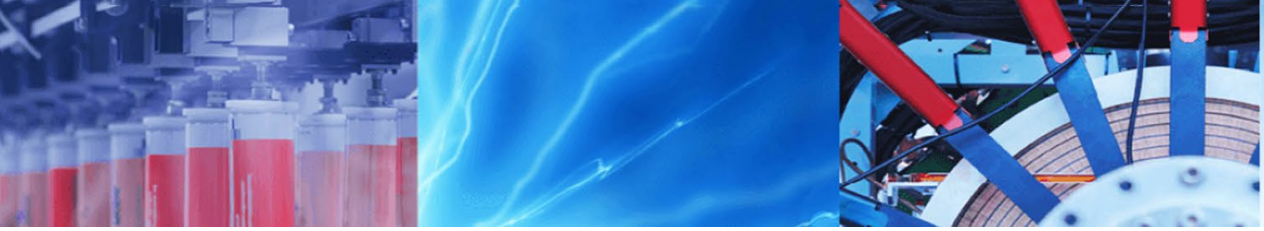

Research Article

\title{
Potential application of nano graphene oxide for saving energy in water thermal desalination system part I
}

\author{
H. S. Hussein ${ }^{1}$ · H. H. Shaarawy ${ }^{1} \cdot$ Nabila H. Hussien ${ }^{1}$ - E. Abdel kader ${ }^{1}$ - S. I. Hawash ${ }^{1}$
}

Received: 24 February 2020 / Accepted: 13 May 2020 / Published online: 20 May 2020

(c) Springer Nature Switzerland AG 2020

\begin{abstract}
Graphene derivatives revolutionize a lot of industries since its discovery. In this investigation nano graphene oxide (NGOCB) was synthesized via sulfuric acid dehydration by mixing of sugar (as source of carbon) with bentonite clay as substrate. NGOCB was characterized by using scaning electron microscope, transmission electron microscope, X-ray diffraction, Fourier transform infrared spectroscopy and scattered area electronic diffraction analysis. The experimental results showed that the particles of graphene oxide are spherical in shape and the diameter ranged from 6 to $33 \mathrm{~nm}$. The data indicated the presence of graphene oxide mono-layers with hexagonal pattern over the bentonite substrate surfaces. On applying the obtained NGOCB in thermal desalination process, several findings were observed such as saving the energy required for reaching the boiling temperature from room temperature by $11 \%$ (NGOCB $4 \mathrm{~g} / \mathrm{l}$ ). While on using $10 \mathrm{~g} / \mathrm{l}$ of NGOCB more than $50 \%$ of the energy consumption for evaporation was saved. Also the generated desalinated water quantity obtained using nano graphene oxide was more than double the quantity that obtained by the traditional thermal desalination method. The generated steam was applied for electricity generation by mini steam turbine, which leads to $22 \%$ energy saving.
\end{abstract}

Keywords Nano graphene oxide · Thermal desalination · Graphene oxide · Conductivity · Solar distillation

\begin{abstract}
Abbreviations
NGOCB Graphene oxide coated on bentonite substrate

NGO Nano graphene oxide

GOSU5 Graphene oxide sugar 5

GOSU7 Graphene oxide sugar 7
\end{abstract}

\section{Introduction}

Graphene oxide (GO) material is remarked by its unique properties that, it composed of hexagonal carbon structure containing oxygen as epoxide, carbonyl, carboxyl and hydroxyl groups. The presence of oxygen inside the crystal structure of GO may lead to easy dispersion in organic solvents and water. Consequently, it facilitates the combination with various materials to improve its mechanical and electrical properties. GO is known as non-conductive hydrophilic carbon based material, easy access and cost effective [1, 2]. In last decades, GO had been synthesized via reaction of potassium chlorate with graphite flakes [3]. Currently, scientists are seeking for environmentally and low cost synthesized nano graphene derivatives. GO could be used in many applications such as graphene production, electronics [4, 5] biomedical [6], solar cells [7-9], graphene/polymer composite materials $[10,11]$, solar stills [12], and water purification [13]. Water desalination is one of the most important graphene applications owing to high cost of the applied desalination technologies. In solar stills, paraffin was dispersed with graphene oxide (0.2, 0.4 , and $0.6 \%$ ) to improve its productivity. The outcome of this investigation may found applications to develop highly efficient solar stills to secure more drinkable water in warm and dry lands [11]. Meanwhile, the addition of nano particles with phase change material enhances the

H. S. Hussein, hala.hussein21@yahoo.com | ${ }^{1}$ Chemical Engineering and Pilot Plant Department, NRC, Giza, Egypt. 
productivity up to $12 \mathrm{~kg} / \mathrm{m}^{2} /$ day which is quite high than the productivity of other conventional stills $\left(5 \mathrm{~kg} / \mathrm{m}^{2} /\right.$ day) $[12,13]$. Also, from the technologies that are mainly utilized, membrane-based reverse osmosis (RO), thermalbased multi-stage flash (MSF) and multi-effect distillation (MED) which consist $90 \%$ of desalination capacity. Moreover, the latest hybrid desalination systems ( RO + MSF, $\mathrm{MED}+\mathrm{MSF}$ ) and pressure-driven reverse osmosis (RO) are potentially applied for seawater desalination. The hybrid (RO, MSF) desalination combines the advantages of the high efficiency of distillation processes and lower energy need for membrane function. It gives a preferable match between water requirements and power that permits better utilization of the power generated from MSF into the $\mathrm{RO}$. Additionally, in (RO) desalination systems, the systems are operated based on passing the high pressure seawater feed through semi-permeable membranes to overcome the osmotic pressure.[14-18]. These system are characterized by high efficiency and productivity of pure water however blocking of membranes may be result in cost elevation. Consequently, the new studies focus on developments of nano scale materials to increase the efficiency and reducing the costs associated with water desalination plants. From these materials, carbon nano tubes, nano wires, graphene compounds, quantum dots, super lattices, and nano shells [19-22]. Graphene derivatives and carbon nanotubes as nano porous membranes have been investigated to enhance the efficiency and productivity of conventional RO membranes [23].Meanwhile, liquids pass easily through the nanoporous membranes compared with the classical membranes [24] wherever, the nano materials exhibit extraordinary strength, great salt rejection and high water fluxes [25]. In future,water treatment seems to be more sophisticated due to development in graphene materials and their applications in water treatment processes [26-32]. Then, graphene derivatives will be beneficially used to maximize the heat transfer and the productivity of fresh water. The main objective of this work to investigate the role of graphene oxide coated on the outer surfaces of bentonite substrate dispersion (as low cost graphene derivative material) in evaporation rate of saline solutions, and saving energy during thermal desalination process.

\section{Experimental}

\subsection{Materials}

All used chemicals are analytical grade: sulfuric acid, nitric acid (El Nasr pharmaceutical chemicals CO.), sodium hydroxide, sugar, and bentonite purchased from Sinai Manganese Co.

\section{SN Applied Sciences}

\subsection{Procedures}

\subsubsection{Synthesis of nano graphene oxide (NGOCB)}

The bentonite clay was mixed with different amounts of sugar as a source of graphene oxide then the procedure of synthesis were carried out as the following:-

a. Bulk bentonite was (particle size $<125 \mu \mathrm{m}$ ) sieved and dried in an oven for $24 \mathrm{~h}$ at $105^{\circ} \mathrm{C}$.

b. About $100 \mathrm{~g}$ clay was mixed with $(1-7 \mathrm{~g})$ of sugar fine powder and stirred on dry state for $5 \mathrm{~min}$.

c. Addition of $200 \mathrm{ml}$ concentrated sulfuric acid was carried out.

d. Heating the mixture gently till the hydration reaction started.

e. After the dehydration reaction completed, addition of $300 \mathrm{ml}$ distilled water was carried out with stirring then boiling the mixture for $30 \mathrm{~min}$. to activate the deposited graphene oxide layer.

f. After cooling the filtration followed by washing is carried out till $\mathrm{pH} 7$, then drying is carried out at $105^{\circ} \mathrm{C}$.

g. After that the dried powder were graphitized by ignition at $800^{\circ} \mathrm{C}$ in inert atmosphere for $5 \mathrm{~h}$ in a muffle furnace.

\subsection{Nano graphene oxide characterization}

\subsubsection{Morphology and particle size}

The surface morphology of the synthesized nano graphene oxide coated bentonite NGOCB was examined by a Carl Zeiss ultra 55 Field Emission Scanning Electron Microscope (FESEM) and JEOL-JEM-1200 Transmission Electron Microscope (TEM). The average diameter of the tested samples was determined from the diameter of 100 nano particles found in several chosen areas in enlarged microphotographs. Also the same electron microscope JEOL-JEM-1200 was used for the examination of the selected area electron diffraction patterns (SAED) tested particles.

\subsubsection{X-ray diffraction}

X-ray diffraction (XRD) for nano graphene oxide coated bentonite were performed with Bruker's D8 advanced $X$-ray diffract meter using CuKa radiation $\left(\lambda=1.5418^{\circ} \mathrm{A}\right)$. Dynamic Light Scattering (Model no: HORIBA Nano particle analyzer SZ100 was used to measure the size of the particle. 


\subsubsection{Fourier transform infrared spectroscopy}

FTIR was performed to identify types of chemical bonds and functional groups in a molecule (Model no: Perkin Elmer precisely FT-IR spectrometer) over the wave number range of $4000-500 \mathrm{~cm}^{-1}$.

\subsection{Evaporation process}

\subsubsection{Evaporation system}

The distillation unit consists of a 304 stainless steel cylindrical vessel of $10 \mathrm{~cm}$ diameter and $20 \mathrm{~cm}$ highest with $2 \mathrm{~cm}$ thickness with actual volume of $2 \mathrm{I}$. This vessel is closed at the bottom by flange good welded with 304 stainless steel by argon gas. The vessel is provided with a screwed flange at the top, sealed with argon. This vessel is connected to pressure gage and steam valve ( 20 bars). The tested pressure is up to 25 bars while the recommended working pressure is 15 bars. This distillation cell is represented in Fig. 1.

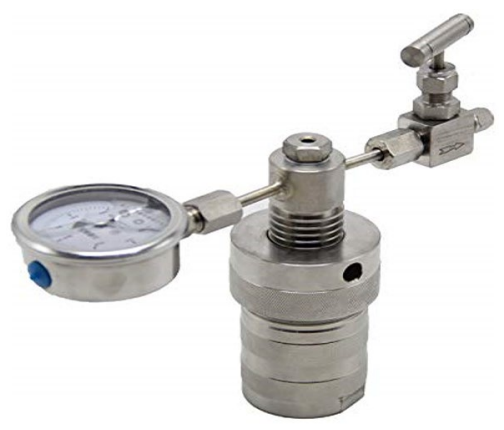

Fig. 1 Distillation unit

\subsubsection{Saline water distillation process}

Figure 2 represents the saline water distillation steps using nano graphene oxide dispersion coated over bentonite clay (NGOCB). As, it is clear from this figure, the setup consists mainly of a distillation cell (s), heating coil, feed water pump, saline water tank (1), mini steam turbine $\left(W_{\mathrm{T}}\right)$, vapor condenser $(C)$, and desalinated water tank. The saline water is pumped from the saline water tank to the distillation column filled with dispersed NGOCB, then boiled by heating using a heating coil. The obtained steam is released from the distillation column to rotate the mini steam turbine to generate electricity, while the outlet steam from the turbine is condensed using steam condenser $(C)$ and stored in the desalinated water tank. The effect of the nano graphene oxide coated on bentonite substrate dose in the evaporation process was investigated to obtain the energy saving efficiency.

\subsubsection{Distillation of saline/nano graphene oxide coated on bentonite substrate}

Different amounts of nano graphene oxide coated on bentonite (NGOCB) were added to salty water $(35 \mathrm{~g} / \mathrm{l})$ in closed system. The temperature was recorded after every $2 \mathrm{~min}$. till reaching the boiling point. Also, after $30 \mathrm{~min}$., from boiling the amount of evaporated water was recorded.

\section{Results and discussion}

\subsection{Type of clay substrate}

The effect of clay type as a substrate for the deposition of graphene layer on the target adsorbent yield was previously investigated by Shaarawy et al. [33]. The conditions
Fig. 2 Experimental setup: distillation cell (s), 1 saline water tank, 2 heating coil, $\mathbf{3}$ mini steam turbine (WT), $\mathbf{4}$ vapor condenser $(C)$ and $\mathbf{5}$ desalinated water tank

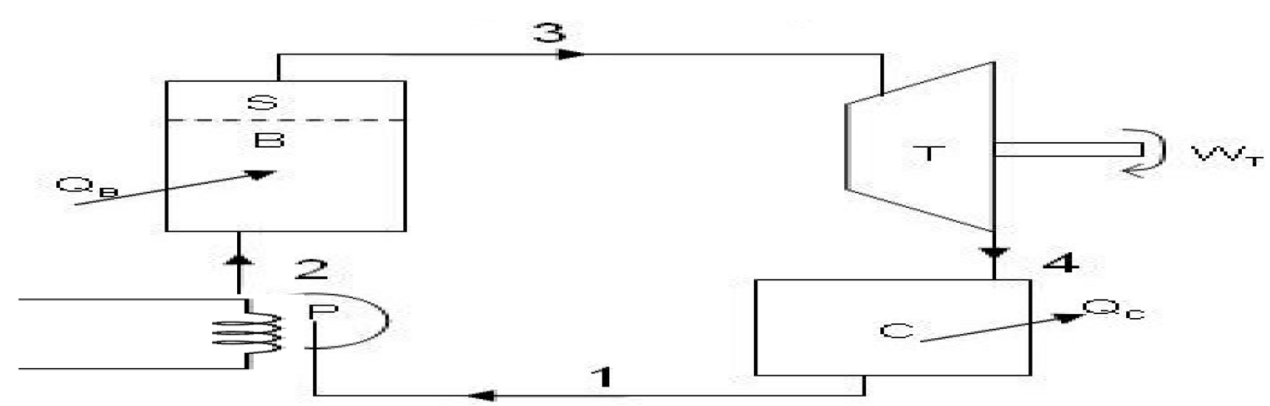

1

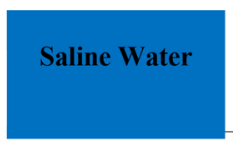

\section{Desalinated Water}


used for the nano graphene oxide coating process over clay surfaces were: clay substrate $100 \mathrm{~g}$, sugar fine powder $5 \mathrm{~g}$, sulfuric acid $100 \mathrm{~g}$, water $300 \mathrm{ml}$, and stirring time $30 \mathrm{~min}$. at $100^{\circ} \mathrm{C}$. Moreover, the bentonite was selected as the most suitable substrate due to its stability against dissolution in the concentrated acids. The stability of bentonite clay may be attributed to the presence of aluminum in combined state with silica, as montmorillonite (sodium/ calcium/aluminum/magnesium/silicate/hydroxide) insoluble hydrated form.

\subsection{Effect of sulfuric acid concentration}

The effect of sulfuric acid concentration on the yield of nano graphene oxide coated on bentonite clay is graphically shown in Fig. 3 . The results showed that, as the sulfuric acid concentration increases the yield of nano graphene oxide decreases. The data revealed that the GO yield \% decreased from $98 \%$ ( $50 \mathrm{ml} / 100 \mathrm{~g}$ clay) to $55 \%$ at $250 \mathrm{ml} / 100 \mathrm{~g}$ clay. So the amount of sulfuric acid $50 \mathrm{ml} / 100 \mathrm{~g}$ clay was selected as the optimum dose.

\subsection{Effect of sugar concentration}

The effect of sugar on bentonite clay with different amounts was previously studied by Shaarawy et al. [33]. the optimum operating conditions for the preparation of NGOCB were $1.5 \mathrm{~kg} / \mathrm{kg}$ clay sulfuric acid concentration, $50 \mathrm{~g} / \mathrm{kg}$ clay sugar fine powder, water $3 \mathrm{l} / \mathrm{kg}$ clay, and stirring time $30 \mathrm{~min}$, at $100^{\circ} \mathrm{C}$.

\subsection{Surface morphology and characterization}

\subsubsection{Scanning electron microscope SEM}

Figure 4 presents SEM micrograph which was taken at $25,000 \times$ magnification to observe nano graphene oxide coated on bentonite substrate morphology. The mean pore diameter was approximately obtained as $33 \mathrm{~nm}$;

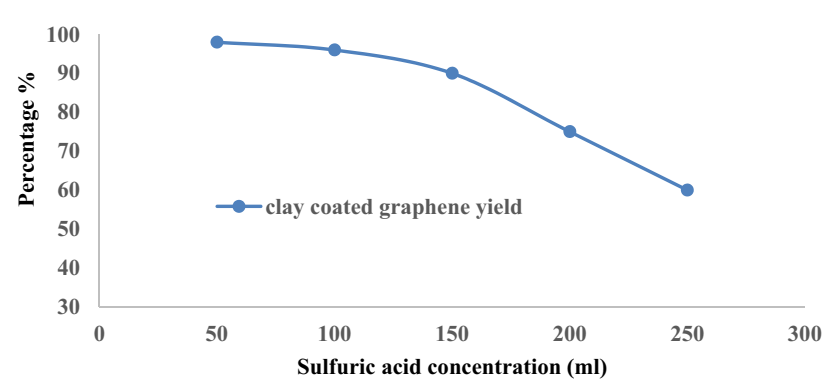

Fig. 3 Effect of sulfuric acid concentration on the nano graphene oxide coated on bentonite, (clay substrate $100 \mathrm{~g}$, and sugar fine powder $5 \mathrm{~g}$, water $300 \mathrm{ml}$, and stirring time $30 \mathrm{~min}$., at $100^{\circ} \mathrm{C}$ )

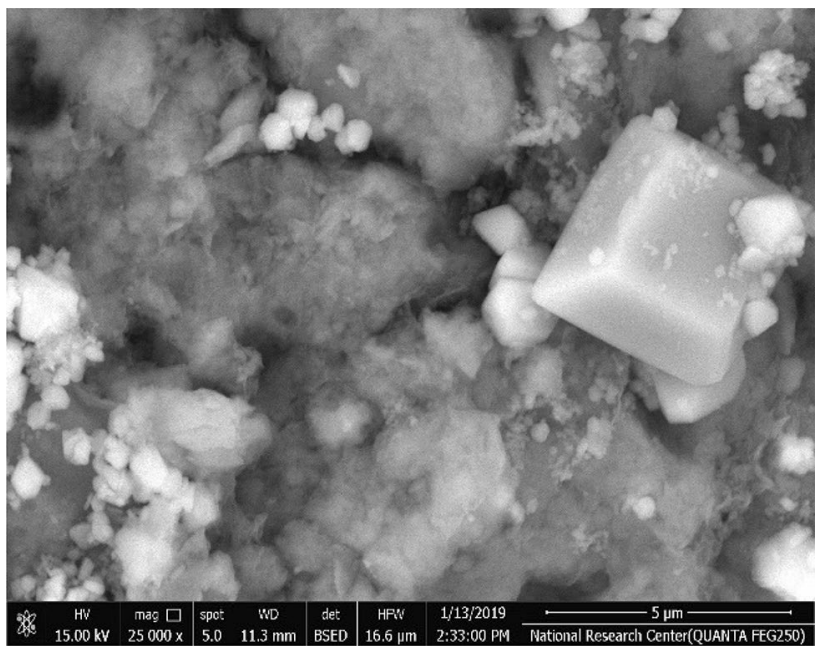

Fig. 4 SEM image of nano graphene oxide coated on bentonite substrate (NGOCB)

also the micrograph shows that the nano graphene oxide coated bentonite surface is porous which shows good adsorption/sorption behavior.

\subsubsection{Transmission electron microscope (TEM) and selected area electron diffraction patterns (SAED) of NGOCB}

NGOCB was prepared at the optmium conditions and characterized by TEM analysis and SAED (Fig. 5a) to obtain the surface morphology. It was found that the obtained particles are spherical in shape of diamter ranged from 6 to $33 \mathrm{~nm}$ as shown in micrograph (a) and the histogram (b) of the prepared sample was shown in Fig. 5. The histogram shows that the major particle sizes present of the optmium NGOCB with a perecentage of $42 \%$ is $6 \mathrm{~nm}$ while the minor particles sizes is $33 \mathrm{~nm}$ which represents $5 \%$ of the sample.

\subsubsection{X-ray diffraction (XRD)}

The XRD analysis of nano graphene oxide was performed to determine its crystal structure that obtained by this method. As shown in Fig. 6, it gave one sharp peak at $15.4^{\circ}$. Moreover, the interlayer distance of graphene oxide (d spacing) was calculated $\left(3.34^{\circ} \mathrm{A}\right)$ which agreed with Birowska et al. [34].

\subsubsection{Fourier transform infrared spectroscopy (FTIR)}

The compositional analysis of nano graphene oxide coated over bentonite surface was performed with the aid of FTIR over the range 390-3890 $\mathrm{nm}$ as shown in Fig.7. The wide band observed in graphene oxide between 3500 and 3100 is attributed to the $\mathrm{O}-\mathrm{H}$ (hydroxyl group), stretching vibrations of $\mathrm{C}-\mathrm{OH}$ and observed water molecules. The peak 


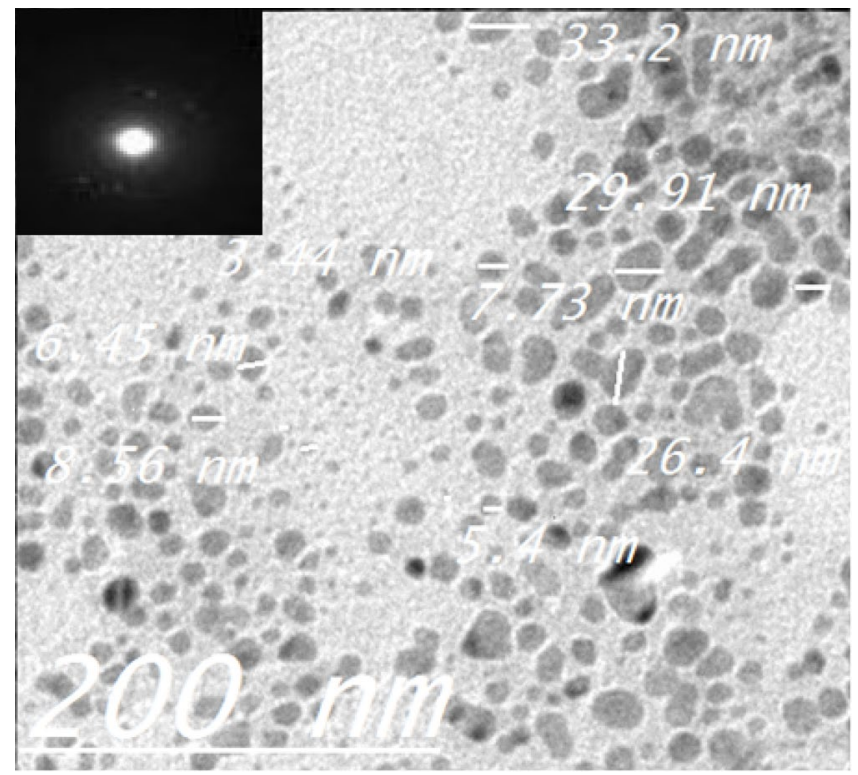

(a)

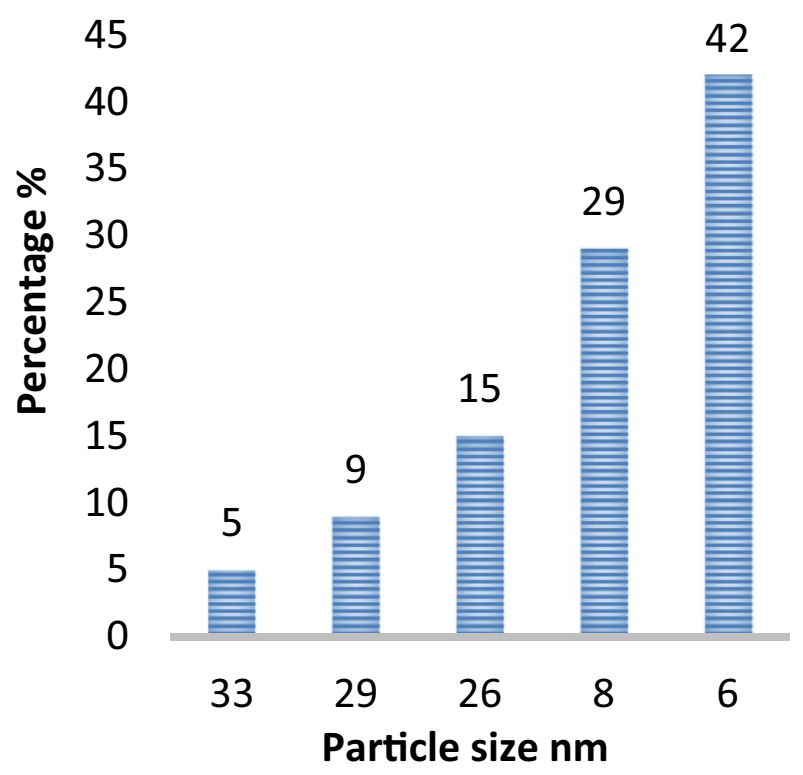

(b)

Fig. 5 a TEM, b SAED histogram of NGOCB at optmium preparation conditions

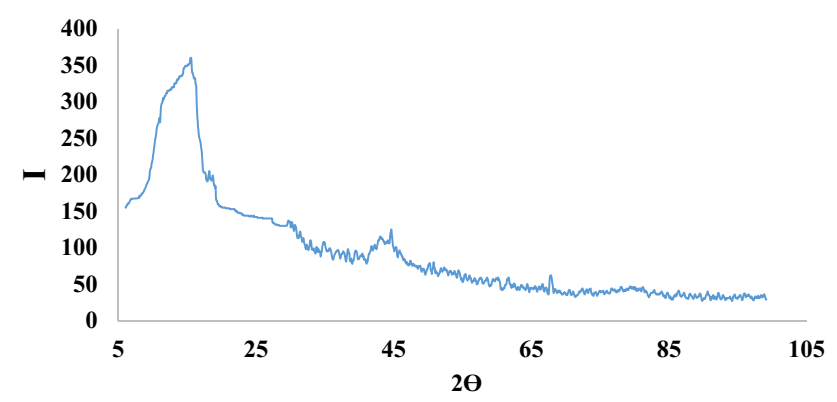

Fig. 6 XRD analysis of nano graphene oxide coated on bentonite

observed at 1627 is due to the combined effect of $C=C$ and $\mathrm{C}=\mathrm{O}$ vibrations. The adsorption bands between $850-800$ $\mathrm{nm}$ are credited to $\mathrm{C}-\mathrm{H}$ bond vibration. Also, spikes at $650-600 \mathrm{~nm}$ arise from $\mathrm{C}-\mathrm{H}$ bonding vibration. Moreover, wide bands that observed between 1087 and 1729.8 are attributed to $\mathrm{C}=\mathrm{O}$ in hydroxyl and $\mathrm{C}=\mathrm{O}$ in carbonyl groups bands at 1226 and $890 \mathrm{~nm}$ which associated with vibration of $\mathrm{C}=\mathrm{C}$ (aromatic) and $\mathrm{C}=\mathrm{O}$ (carbonyl) [34]. The presence of carbonyl group $\mathrm{C}=\mathrm{O}$ indicates the presence of nano graphene oxide formed due to the acid dehydration of sugar over bentonite substrate.

\subsection{Role of sugar amount used for preparation of NGOCB on salty water boiling time}

Figure 8 shows the effect of sugar concentration as a source of graphene oxide nano particles coated over the

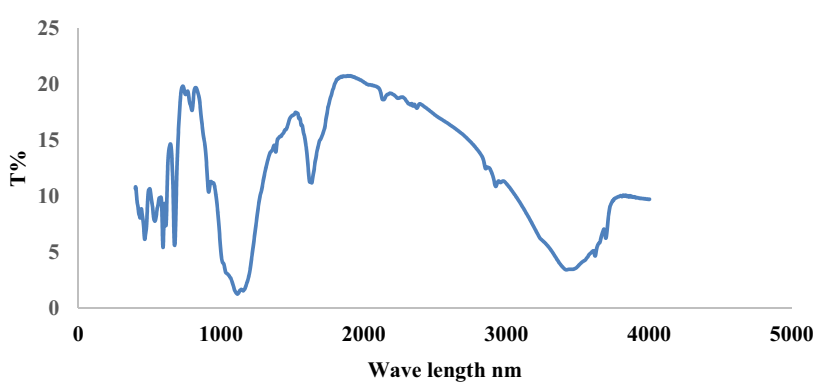

Fig. 7 FTIR analysis of nano graphene oxide coated on bentonite substrate (NGOCB)

surface of bentonite clay on the time required for saline water boiling. It is clear from the results that no significant change obtained due to increment of sugar concentration from $50 \mathrm{~g} / \mathrm{kg}$ to $70 \mathrm{~g} / \mathrm{kg}$ clay. Consequently, the amount $50 \mathrm{~g}$ sugar $/ \mathrm{kg}$ of bentonite clay was taken as optimum dose because this value decreases the time required for saline water boiling from $15 \mathrm{~min}$. to $14.1 \mathrm{~min}$. which results about $6 \%$ of energy saving.

\subsection{Effect of nano graphene oxide coated bentonite (NGOCB) dose on boiling time}

Figure 9 shows the effect of NGOCB concentration on the boiling time of saline water (saline sample was $50 \mathrm{ml}$.), the results showed that, the time required to reach the boiling degree was $15 \mathrm{~min}$. for both the pure saline and saline water containing $0.1 \mathrm{~g} \mathrm{NGOCB}$ particles. This may 
Fig. 8 Effect of sugar concentration as source of nano graphene oxide coated on bentonite clay on boiling time of salty water

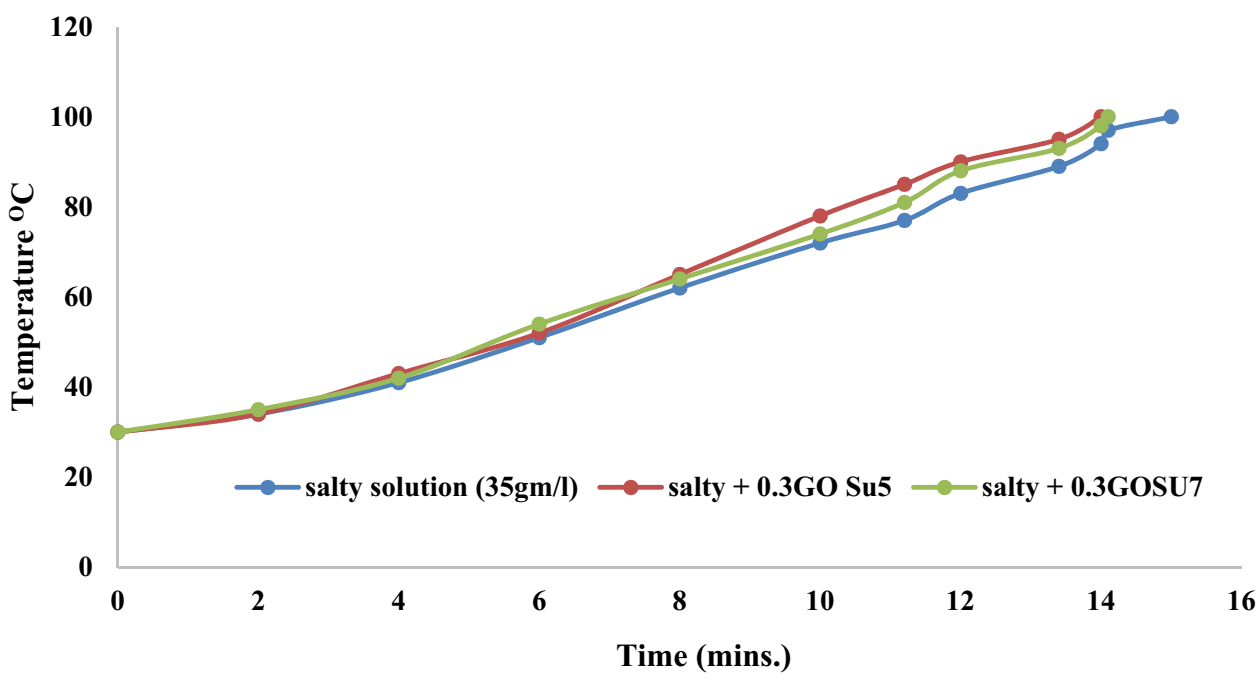

be due to the amount of nano graphene oxide was insufficient to exceed the hydrogen bond strength between the water molecules. It was noticed that the optimum dose of nano graphene oxide was $0.2 \mathrm{~g} / 50 \mathrm{ml}$ saline $(4 \mathrm{~g} / \mathrm{l}) \mathrm{NGOCB}$. Meanwhile, this dose was sufficient to exceed all the hydrogen bonds between water molecules and permits the water boiling in a shorter time compared with pure saline water. Upon addition of NGOCB more than $0.2 \mathrm{~g}$ the saline solution viscosity increased which increase the time required for boiling. Hence, $4 \mathrm{~g} / \mathrm{l}$ of NGOCB will be taken as optimum dose and from the calculation, it was found that energy saving via this dose is about $11 \%$.

\subsection{Rate of evaporation}

Figure 10 shows the rate of evaporation of saline water mixed by NGOCB ( $4 \mathrm{gm} / \mathrm{l}$ and $10 \mathrm{gm} / \mathrm{l})$. The amount of vapor is recorded after reaching the boiling point for $30 \mathrm{~min}$. The rate of vaporization of saline water with nano graphene oxide is represented by linear equations and listed in Table 1, that is presented as follows:

For $4 \mathrm{gm} / \mathrm{l} \quad \mathrm{EV}=0.4818 \times \mathrm{ET} \quad\left(R^{2}=0.9983\right)$

For $10 \mathrm{gm} / \mathrm{l} \quad \mathrm{EV}=0.596 \times \mathrm{ET} \quad\left(R^{2}=0.9923\right)$

where EV is vapor volume, and ET Evaporation time (min.) after reaching the boiling degree. Also, as the evaporation time increases, the amount of vapor increases as well.

\subsection{Energy saving}

On the other hand, Fig. 11 shows the energy saving value on using different doses of dispersed (NGOCB)
Fig. 9 Effect of nano graphene oxide coated bentonite (NGOCB) dose on the boiling time of saline water

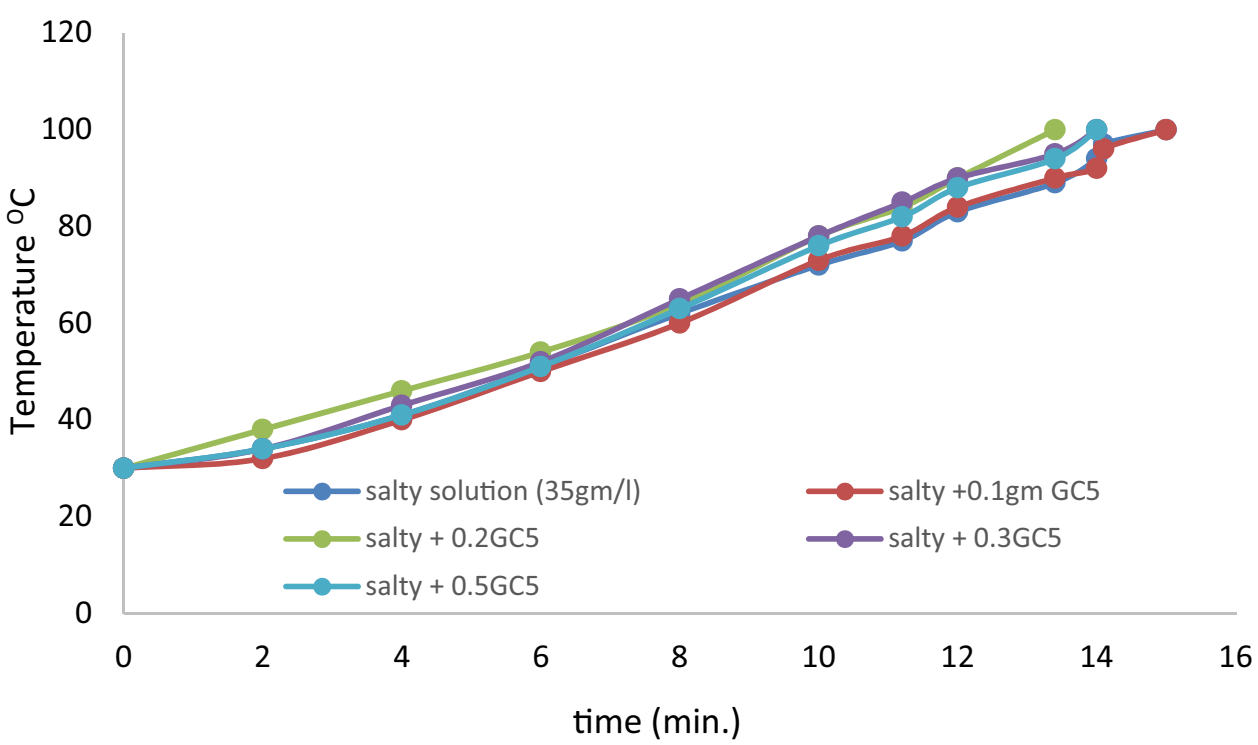


Fig. 10 Amount of vapor formed during $30 \mathrm{~min}$, after boiling time at $4 \mathrm{~g} / \mathrm{l}$, and $10 \mathrm{gm} / \mathrm{l}$ of NGOCB

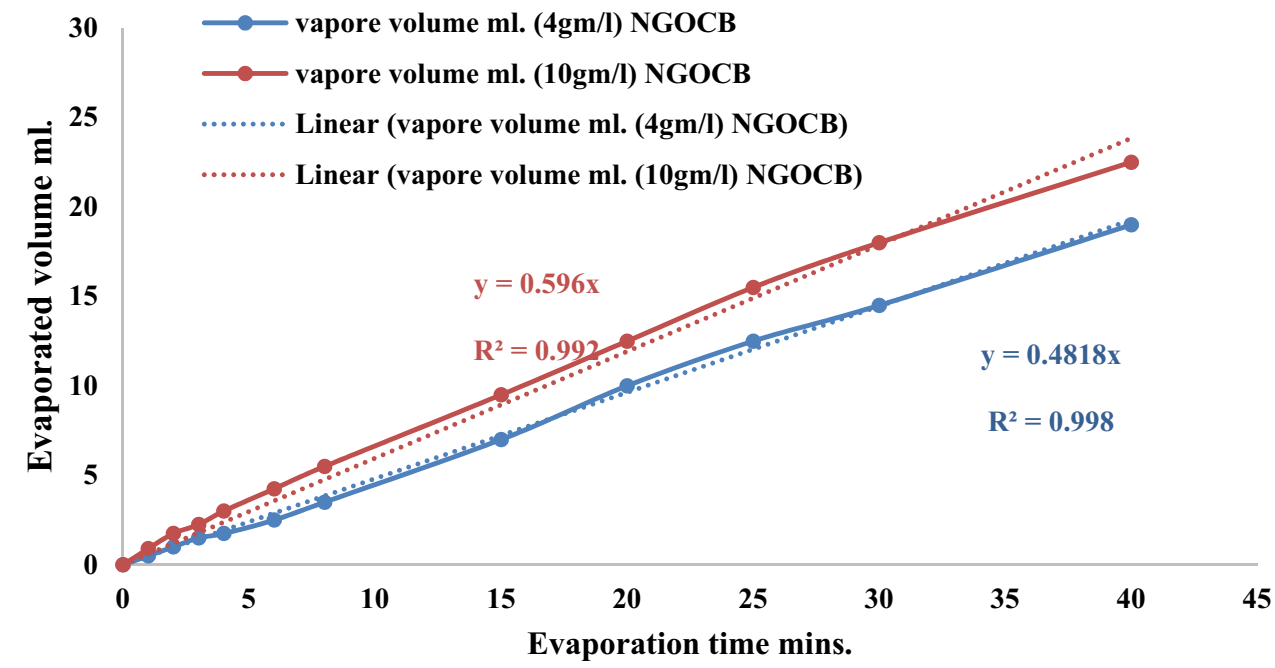

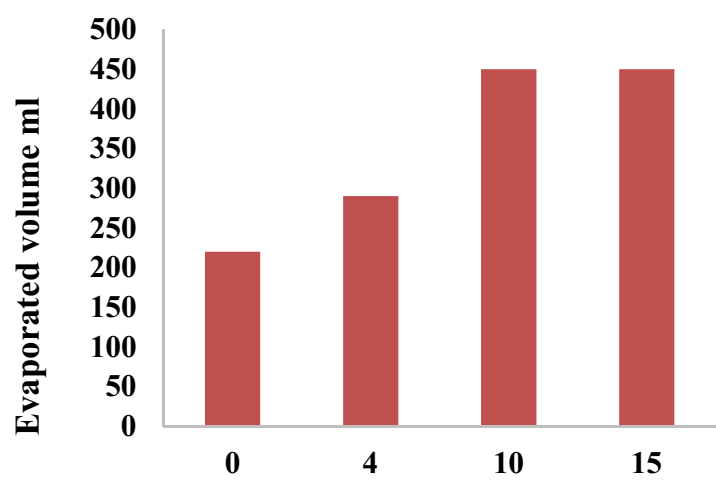

NGOCBdose $\mathrm{g} / \mathbf{l}$

(b)

Fig. 11 Effect of NGOCB dose on the vapor volume during $30 \mathrm{~min}$. after boiling point, a time required for boiling, and $\mathbf{b}$ vapor volume generated with time after boiling

Table 1 The effect of nano graphene oxide concentration on the rate of vaporization

\begin{tabular}{lll}
\hline $\begin{array}{l}\text { Amount of nanographene oxide } \\
\text { coated bentonite }(\mathrm{g} / \mathrm{l})\end{array}$ & Rate of vaporization & $\mathrm{R} 2$ \\
\hline 4 & $0.4818 \times \mathrm{ET}$ & 0.9983 \\
10 & $0.596 \times \mathrm{ET}$ & 0.9923 \\
\hline
\end{tabular}

during saline water evaporation for $30 \mathrm{~min}$. after reaching the boiling. The results show that as the (NGOCB) dose increases from $0 \mathrm{~g} / \mathrm{l}$ of saline water to $10 \mathrm{~g} / \mathrm{l}$ of saline water. The amount of vapor increases from 220 to $450 \mathrm{ml}$ as shown in Fig. $11 \mathrm{~b}$, the energy consumption increasing by $10 \%$ to reach the boiling degree as shown in Fig. 11 a. However, after 30 min. from boiling, the volume percent of vapor in case of $10 \mathrm{~g} / \mathrm{l}$ of nano graphene oxide coated on bentonite substrate is $204.5 \%$ of that obtained in case of saline water only. Meanwhile, the energy consumed for distillation of pure saline water is double the amount required for distillation of saline water comprising $10 \mathrm{~g} / \mathrm{l}$ NGOCB. Consequently, NGOCB is decreasing energy consumption nearby $50 \%$.These findings may clarified as retarding of boiling time on addition of $10 \mathrm{~g} / \mathrm{l}$ graphene oxide may be attributed to increase in solution viscosity. Moreover, the enhancing of vapor amount in case of addition of graphene to saline water is explained by the graphene ability to reduce the contact angle between the liquid and vapor interface. On the other hand, NGOCB may be able to break the hydrogen bonds between water molecules. 
In this work, the behavior of a water nano-droplet on hydrophilic nano graphene oxide coated on bentonite substrate (NGOCB) is studied at high temperatures to investigate the possibility of saving energy in the evaporation of saline solution. The results showed that, as the temperature is increasing, the spreading will exceed the evaporation of water molecules on the surface of NGOCB. At high temperatures, the regime changes from partial to total wetting. After the spreading is completed and the surface is completely covered by water, evaporation of water occurs more rapidly. Simulation results revealed that as the system temperature rises, the number of hydrogen bonds between water molecules decreases.

As the temperature increases, the hydrogen bond between the water molecules disintegrates and is replaced by formation of new hydrogen bonds between the water molecules and the nano graphene oxide coated bentonite molecules. The bond strength between water and nano graphene oxide coated bentonite (NGOCB) may be more feeble than the hydrogen bonds existing between the water molecules, which facilitates the evaporation of water from the NGOCB surface.

In terms of the contact angle and the density of the water molecules on the surface of the NGOCB as temperature increases water molecules largely expanded on the surface of $N G O C B$, that increases the amount of water vapors on the surface of NGOCB. Regarding to water molecules dipolar momentum at several layers of NGOCB indicate that water molecules in the initial layers tend to approach the surface with hydrogen atoms. Hence, the possibility of evaporation of water molecules at high temperatures, complete wetting on the GO substrate could be detected in nearly one nanosecond. Afterward, water evaporation occurs more rapidly after the completion of dispersion and full coverage of the surface by water. Lastly, the elevation of temperature leads to an increase in the number of evaporated water molecules on the GO surface [35].

From the point of view of evaporation energy, the energy required to convert one kilogram of saline water into steam during distillation process is nearly $720.1 \mathrm{Kwt}$. Meanwhile, there is about $93 \mathrm{Kwt}$ consumed for water boiling (from room temperature) and $627.1 \mathrm{kwt}$ is spent to convert the boiled water to steam. Also, on the addition of $4 \mathrm{~g} / \mathrm{l}$ (NGOCB) to the saline water, it was noticed that, the energy saving for desalination near to $11 \%$ (from room temperature to boiling). However, on using $10 \mathrm{~g} / \mathrm{l}$ (NGOCB), no energy saving was recorded during the change in temperature elevation till boiling. on the other hand, during evaporation process after boiling for $30 \mathrm{~min}$. in the evaporation cell (heating coil of $500 \mathrm{Wt}$./h., with volume capacity one I), the time required for reaching boiling is about $17 \mathrm{~min}$. while the evaporation is carried for $30 \mathrm{~min}$. with total experiment time $47 \mathrm{~min}$.

From calculations, one $\mathrm{kg}$ of saline water required $2.272 \mathrm{kWt}$ to produce one $\mathrm{kg}$ steam while in case of nano graphene oxide coated bentonite suspension, only $0.871 \mathrm{kwt}$ is required. Meanwhile, the same energy for evaporation of saline water mixed by nano graphene oxide coated bentonite, more than $240 \%$ of water vapor could be produced compared with pure saline water.

Using mini steam turbine to recover electricity from the generated steam shows energy recovery of $21 \%$ $(0.183 \mathrm{kt} / \mathrm{h})$ for nano graphene oxide coated bentonite substrate suspension. So, from the above results and calculations, it was found that one $\mathrm{kg}$ of vapor formation during distillation (in presence of NGOCB)the amount of electricity recovery using mini steal turbine required was about $0.688 \mathrm{kwt}$./hr. While, it was required $2.272 \mathrm{~K} \mathrm{Wt}$./h. in absence of NGOCB, Energy saving reached to about $58.23 \%$.

\subsection{Economic indicators}

For economic indicators prediction for the production process of nano graphene oxide coated over the outer surface of bentonite clay using the reaction of sulfuric acid with fine crushed sugar, we made a hypothetically design for production unit with daily capacity of 1 ton. The proposed unit based on st.st double jacket st.st $316 \mathrm{~L}$ mixer, boiler, filtration system, thermal dryer, RO desalination unit, liquid nano potassium sulfate fertilizer unit, filing machine, backing unit, and other helping auxiliaries such as balance, forklift, analysis apparatus. Economic analysis was carried out using excel program calculations. The program shows that the electromechanical equipment cost will be 441 thousand $\$$ including the installation, maintenance, control, electricity, and transportation. The civil work will cost 571 thousand \$, while the working capital cost is 695 thousand \$ including the material cost for three months with $15 \%$ added value taxes, indirect cost, labor, and energy. The indirect cost is 0.6 million $\$$ and the annual labors including insurance is 3.66 million $\$$. The products generated in the proposed plant is 330 ton/year of graphene oxide coated on bentonite, and 12 ton liquid nano potassium fertilizer. The nano graphene oxide coated bentonite will be sale as $25 \mathrm{~kg}$ package, while the liquid nano fertilizer will be sale as 25 liter bottle capacity. The results show that the annual depreciation is 56.8 thousand $\$$. The study indicates that the required investment is 3.9 Million \$. The total annual production cost is 2.6 million $\$$ with cost of one ton $4000 \$$ for graphene oxide product and $3806 \$$ for each ton of nano potassium fertilizer. The proposed price is $15,000 \$$ /ton of graphene oxide product and $70 \$$ for each 25 liter capacity nano fertilizer bottle. 
The annual sales is 11.38 Million $\$$ with annual gross 8.8 Million \$. The annual tax (25\% of the annual gross) is 2.2 million \$. The annual net profit is 6.6 million $\$ .50 \%$ of the net profit will be directed as divined, commissions, and Pay the loan installments i.e. 3.3 million \$. The rest is directed as cash flow i.e. 3.3 Million $\$$ annually. Based on the above calculations the predicted internal rate of return is $80.16 \%$.

All the indicators show high profitability, strong and stable financial position, and a very high cash flow. The feasibility study shows a high liquidity rate as the average liquidity ratio of 1: 9 exceeds on average, indicating very high liquidity. Solid financial structure as the leverage rate is equal to $0.8: 1$ and then as a final result due to the technology of nanoscience it is expected that the project will achieve very high profits, stable financial structure and high liquidity.

\section{Conclusions}

In this study, NGOCB composite was prepared by treating bentonite clay with sugar.

The results show that the behavior of the nano-droplet water on NGOCB surface was investigated at different temperature. At high temperature, water molecules dispersed on the NGOCB surface and water evaporation occurs more rapidly. Increasing temperature leads to increase the number of evaporated water molecules in the initial layers of NGOCB.

Energy used to distillate water from saline solutions can be decreased by $50 \%$ in case of using NGOCB as dispersion in the solution or as a liner for internal walls of the evaporator. The amount of NGOCB, more than $4 \mathrm{~g} / \mathrm{l}$ saline water leads to increase in viscosity and the time required for boiling.

Regarding electricity output then heat recovery from hot condensate, appropriate design of desalination system will be cost effective which needs more investigations.

Acknowledgements The authors thank the National Research Center of the Arab Republic of Egypt for funding research and technical support through chemical and physical analysis by the central laboratories within the National Research Center.

Author contributions All authors participated in the development and implementation of the research plan and subsequently written it. All authors read and approved the final manuscript.

\section{Compliance with ethical standards}

Conflict of interest The authors declare no conflicts of interest.

\section{References}

1. Higginbotham AL, Lomeda JR, Morgan AB, Tour JM (2009) Graphite oxide flame retardant polymer nano composites. Appl Mater Interfaces 1:2256-2261

2. Lerf A, He H, Forster M, Klinowski J (1998) Structure of graphite oxide revisited. J Phys Chem B 102:4477-4482

3. Brodie BC (1859) On the Atomic Weight of Graphite. Philos Trans R Soc Lond 149:249-259

4. Su C-Y, Xu Y, Zang W, Zhao J, Liu A, Tang X, Tsai C-H, Huang Y, Li L-J (2010) Highly efficient restoration of graphitic structure in graphene oxide using alcohol vapors. ACS Nano 4:5285-5292

5. Wang S, Ang P, Wang Z, Tang A, Thong J, Loh K (2010) High mobility, printable, and solution-processed graphene electronics. Nano Lett 10:9298

6. Cai B, Wang S, Huang L, Ning Y, Zhang Z, Zhang G-J (2014) ultrasensitive label-free detection of PNADNA hybridization by reduced graphene oxide field-effect transistor biosensor. ACS Nano 8:2632-2638

7. Matyba P, Yamaguch H, Eda G, Chhowalla M, Edman L, Robinson N (2010) Graphene and mobile ions: the key to allplastic, solution-processed light-emitting devices. ACS Nano 4:637-642

8. Becerril HA, Mao J, Liu Z, Stoltenberg RM, Liu Z, Chen Y et al (2008) Evaluation of solution-processed reduced graphene oxide films as transparent conductors. ACS Nano 2:463-470

9. Saha SK, Bhaumick S, Maji T, Mandal TK, Pal AJ (2014) Solutionprocessed reduced graphene oxide in light-emitting diodes and photovoltaic devices with the same pair of active materials. RSC Adv 4:35493-35499

10. Li S-S, Tu K-H, Lin C-C, Chen C-W, Chowilla M (2010) Solutionprocess able graphene oxide as an efficient whole transport layer in polymer solar cells. ACS Nano 4:3169-3174

11. Safaei MR, Goshayeshi HR, Chaer I (2019) Solar still efficiency enhancement by using graphene oxide/Parafn Nano-PCM". Energies 12:1-13

12. Hu X, Xu W, Zhou L, Tan Y, Wang Y, Zhu S, Zhu J (2017) Tailoring graphene oxide-based aerogels for efficient solar steam generation under one sun. Adv Mater 29(5):1604031

13. Dsilva D, Rufuss W, Iniyana S, Suganthi L, Daviesc PA, Akinaga T, (2016). Analysis of solar still with nanoparticle incorporated phase change Conference: ISES Solar World Congress

14. Ali I, Alharbi OML, Tkachev A, Burakov EGA, Grachev VA (2018) Water treatment by new-generation graphene materials: hope for bright future. Environ Sci Pollut Res 25:7315-7329

15. Son HS, Shahzad MW, Ghaffour N, Ng KC (2020) Pilot studies on synergetic impacts of energy utilization in hybrid desalination system: Multi-effect distillation and adsorption cycle (MED-AD). Desalination 477:114266

16. Shahzad MW, Ng KC (2017) An improved multievaporator adsorption desalination cycle for gulf cooperation council countries. Energy Technol 5(9):1663-1669. https://doi. org/10.1002/ente.201700061

17. Muhammad Wakil Shahzad and Kim Choon Ng (2016) On the Road to Water Sustainability in the Gulf. Nature Middle East. https://doi.org/10.1038/nmiddleeast.2016.50

18. Shahzad MW, Ng KC, Thu K (2016) Future sustainable desalination using waste heat: kudos to thermodynamic synergy. Environ Sci Water Res Technol 2(1):206-212

19. Shahzad MW, Burhan M, Ang L, Ng KC (2017) Energy-waterenvironment nexus underpinning future desalination sustainability. Desalination 413:52-64

20. Shahzad MW, Burhan M, Son HS, Oh SJ, Ng KC (2018) Desalination processes evaluation at common platform: a universal performance ratio (UPR) method. Appl Therm Eng 134:62-67 
21. Ng KC, Shahzad MW, Son HS, Hamed OA (2017) An exergy approach to efficiency evaluation of desalination. Appl Phys Lett 110(18):184101

22. Shahzad MW, Burhan M, Ng KC (2019) A standard primary energy approach for comparing desalination processes. Nat Clean Water 1:1-7. https://doi.org/10.1038/s41545-018-0028-4

23. Shahzad MW, Burhan M, Ybyraiymkul D, Ng KC (2019) Desalination processes' efficiency and future roadmap. Entropy 21(1):84

24. Al-Mutaz IS (2003) Hybrid RO MSF: a practical option for nuclear desalination. Int J Nuclear Desalination 1:1-11

25. Gogotsi Y (2006) Carbon nanomaterials. Taylor and Francis, Boca Raton, p 326

26. Baughman RH, Zakhidov AA, De Heer WA (2002) Carbon nanotubesthe route toward applications. Science 297:787-792

27. Novoselov KS, Geim AK, Morozov SV, Jiang D, Zhang Y, Dubonos SV, Grigorieva IV, Firsov AA (2004) Electric field effect in atomically thin carbon films. Science 306:666-669

28. Holt JK, Park HG, Wang YM, Stadermann M, Artyukhin AB, Grigoropoulos CP, Noyand A, Bakajin O (2006) Fast mass transport through sub-2-nanometer carbon nanotubes. Science 312:1034

29. Lee C, Wei X, Kysar JW, Hone J (2008) Measurement of the elastic properties and intrinsic strength of monolayer graphene. Science 321(5887):385-388

30. Khan A, Wang J, Li J, Wang X, Chen Z, Hayat TA, Chen Y (2017) The role of graphene oxide and graphene oxide-based nanomaterials in the removal of pharmaceuticals from aqueous media: a review. Environ Sci Pollut Res 24(9):7938-7958

31. Nidheesh PV (2017) Graphene-based materials supported advanced oxidation Processes for water and wastewater treatment: a review. Environ Sci Pollut Res 24(35):27047-27069

32. Riaz MA, McKay G, Saleem J (2017) 3D graphene-based nanostructured materials as sorbents for cleaning oil spills and for the removal of dyes and miscellaneous pollutants present in water. Environ Sci Pollut Res 24(36):27731-27745

33. Shaarawy $\mathrm{HH}$, Hussein $\mathrm{HS}$, Abdel Kader $\mathrm{E}$, Hussien Nabila $\mathrm{H}$, Hawash SI (2020) Adsorption performance of coated bentonite via graphene oxide. BNRC 44:53

34. Birowska M, Milowska K, Majewski JA (2011) Van Der Waals density functional for graphene layers and graphite. Acta Physica Polonicaa 120:845-848

35. Zahedi H, Foroutan M (2018) Molecular dynamics simulation of a water nano-droplet on graphene oxide surface at high temperature: Evaporation or spreading. Appl Surf Sci 455:789-794

Publisher's Note Springer Nature remains neutral with regard to jurisdictional claims in published maps and institutional affiliations. 